\title{
Efetividade de agentes químicos na desinfecção de tubetes anestésicos
}

Effectiveness of chemical agents for disinfecting anesthetic tubes

João Ricardo Alves Pauletti
Francine Daiane Lauermann
Gabriela Marchesan Savy*
Adriana Corsetti**
Angelo Luiz Freddo ${ }^{* * *}$

\section{Resumo}

Objetivo: avaliar a efetividade da desinfecção de tubetes anestésicos, in vitro, para procedimentos cirúrgicos ambulatoriais, utilizando álcool $70 \%$ (A), composto de iodo (I) solução aquosa de digluconato de clorexidina $0,12 \%$ (CA $0,12 \%$ ), solução aquosa de digluconato de clorexidina $2 \%$ (CA $2 \%)$, solução alcoólica de digluconato de clorexidina $0,12 \%$ (CAL $0,12 \%$ ), solução alcoólica de digluconato de clorexidina 2\% (CAL 2\%). Materiais e método: como grupos controle utilizou-se a água destilada (D) e nenhum agente (SN). Após os tempos de exposição de 5, 10 e 15 minutos aos agentes desinfetantes realizou-se coleta das amostras com swab que foram embebidas em caldo de tripticase de soja (TSB) e os tubos incubados a $37^{\circ} \mathrm{C}$ por 24 horas. As amostras foram inoculadas em placas de Petri contendo meio tripticase de soja ágar (TSA) e incubadas a $37^{\circ} \mathrm{C}$ por 48 horas, verificando a presença ou ausência de Unidades Formadoras de Colônias (CFU). Resultados: o estudo revelou que A e CA $0,12 \%$ foram efetivos apenas após 15 minutos de exposição. As soluções CA $2 \%, C A L \quad 0,12 \%$, CAL $2 \%$ e I foram efetivos nos tempos experimentais de 5, 10 e 15 minutos. Nos grupos controles ( $D$ e $\mathrm{SN}$ ) houve crescimento bacteriano em todos os tempos experimentais. Conclusões: os agentes testados que demonstraram eficácia de desinfecção já em 5 minutos, associada ao baixo custo e facilidade de manipulação, foram: I, CA 2\%, CAL 0,12\%, CAL 2\%. O resultado do grupo controle evidencia a necessidade de desinfecção dos tubetes previamente ao seu uso.

Palavras-chave: Desinfecção. Assepsia. Compostos químicos. Cirurgia bucal.

\section{Introdução}

Em toda atividade odontológica, tão importante quanto o aprimoramento técnico e científico é a conscientização dos riscos de contaminação e infecção durante o atendimento. Com a finalidade de reduzir o número de microrganismos presentes em instrumento ou superfície, um dos procedimentos comumente utilizados na odontologia é a desinfecção. Segundo Block ${ }^{1}$ (2001) a desinfecção é a destruição de patógenos e outros tipos de microrganismos por mecanismos térmicos e químicos, mas não em todas as formas, como os esporos bacterianos.

Diversos agentes podem ser utilizados para a desinfecção de instrumentos. Dentre os existentes, os que serão analisados no estudo são: solução aquosa de digluconato de clorexidina $0,12 \%$, solução alcoólica de digluconato de clorexidina $0,12 \%$, solução aquosa de digluconato de clorexidina $2 \%$, solução alcoólica de digluconato de clorexidina $2 \%$, álcool $70 \%$ e compostos de iodo. Almejando o sucesso da desinfecção, deve-se conhecer do agente o mecanismo de ação sobre os microrganismos, toxicidade para 0 manipulador e ação deletéria para o equipamento a ser desinfetado ${ }^{2}$.

As soluções de digluconato de clorexidina, tanto alcoólica quanto aquosa, são anti-sépticos químicos, com ação antifúngica, bactericida e bacteriostática. O mecanismo de ação decorre da diminuição da tensão superficial e da estrutura proteica, através de desnaturação das membranas celulares ${ }^{3}$.

${ }_{* *}^{*}$ Prof Adjunto Faculdade de Odontologia UFRGS, Mestre e Doutor em CTBMF 
O álcool etílico $70 \%$ e o álcool isopropílico são considerados desinfetantes de nível intermediário, empregados tanto na desinfeção de superfícies e instrumentos como na antissepsia da pele ${ }^{4}$. $\mathrm{O}$ álcool tem ação limitada, uma vez que evapora rapidamente, havendo necessidade de imersão de objetos para uma ação mais ampla ${ }^{5}$. O composto de iodo mais usado é o álcool iodado a $0,5 \%$ ou $1 \%$. A solução de iodo deve ser preparada semanalmente e condicionada em frasco âmbar com tampa fechada, para evitar deterioração e evaporação e devidamente protegido da luz e calor. Ele é um agente bactericida com atividade esporicida, fungicida e, de certo modo, ativo contra vírus ${ }^{6}$.

Além dos agentes utilizados na pesquisa, há outras substâncias também preconizadas para desinfecção, como o Ácido Paracético e o Glutaraldeído $2 \%$. Porém, apesar das características antimicrobianas, o ácido paracético apresenta alto potencial corrosivo para a maioria dos metais, possuindo características de reatividade e toxicidade. Seu vapor é irritante aos olhos, nariz e garganta. O Glutaraldeído libera vapores tóxicos, possuindo risco ocupacional quando absorvido pelas vias oral, dérmica e/ou inalatória e apresenta elevado potencial de irritabilidade ${ }^{7}$. Por essas desvantagens, tornaram-se inviáveis para a pesquisa.

Visando garantir que ocorra uma desinfecção desejada, o estudo objetiva avaliar a efetividade da desinfecção de tubetes anestésicos, in vitro, para procedimentos cirúrgicos ambulatoriais, utilizando álcool 70\% (A), composto de iodo (I) solução aquosa de digluconato de clorexidina $0,12 \%$ (CA $0,12 \%$ ), solução aquosa de digluconato de clorexidina $2 \%$ (CA $2 \%$ ), solução alcoólica de digluconato de clorexidina $0,12 \%$ (CAL $0,12 \%$ ), solução alcoólica de digluconato de clorexidina $2 \%$ (CAL $2 \%$ ).

\section{Materiais e método}

$\mathrm{O}$ presente estudo foi de natureza experimental para análise in vitro, controlado, realizado no Laboratório de Bioquímica e Microbiologia Bucal (LABIM) da Faculdade de Odontologia da UFRGS (FO-UFRGS)

Para testar a eficácia da desinfecção dos tubetes anestésicos usualmente utilizados na FO-UFRGS - cloridrato de lidocaína 2\% (DFL Indústria e Comércio S.A, Rio de Janeiro, RJ) com epinefrina acondicionados em tubetes de vidro de $1,8 \mathrm{ml}$ - em procedimentos cirúrgicos ambulatoriais, utilizou-se álcool 70\% (A), composto de iodo (I), solução aquosa de digluconato de clorexidina $0,12 \%$ (CA $0,12 \%$ ), solução aquosa de digluconato de clorexidina $2 \%$ (CA $2 \%$ ), solução alcoólica de digluconato de clorexidina $0,12 \%$ (CAL $0,12 \%$ ) e solução alcoólica de digluconato de clorexidina $2 \%$ (CAL 2\%). Como controle utilizou-se água destilada (D) e nenhum agente (SN).
Os tubetes anestésicos são habitualmente retirados da caixa de comercialização e colocados em potes plásticos abertos em contato com o meio externo, misturando lotes, tornando-os acessíveis aos alunos da faculdade. Para o estudo, foram retirados do local de armazenamento no ambulatório de cirurgia da FO-UFRGS e utilizados 72 tubetes de anestésico. Os quais foram divididos em oito grupos (nove tubetes/grupo), nomeados pelos agentes desinfectantes e separados para serem testados em três tempos diferentes (cinco, dez e quinze minutos), formando uma tríade. A solução CAL $0,12 \%$, A, I e CAL $2 \%$ foram adquiridos na Faculdade de Odontologia da UFRGS. Foram adquiridas pelo pesquisador as soluções CA 0,12\% (Farmácia Essência Vital [Manipulação], São Leopoldo, RS) e CA 2\% (Farmácia Suzana [Manipulação], Porto Alegre, $\mathrm{RS})$. Os valores em reais dos agentes químicos utilizados na pesquisa encontram-se no Quadro 1:

Quadro 1 - Valor de mercado dos agentes

\begin{tabular}{|c|c|c|c|c|c|c|}
\hline & $\begin{array}{c}\mathrm{A} \\
(250 \mathrm{~mL})\end{array}$ & $\begin{array}{c}\mathrm{I} \\
(250 \mathrm{~mL})\end{array}$ & $\begin{array}{c}\text { CAL 0,12\% } \\
(250 \mathrm{~mL})\end{array}$ & $\begin{array}{c}\text { CA 2\% } \\
(250 \mathrm{~mL})\end{array}$ & $\begin{array}{c}\mathrm{CAL} 2 \% \\
(250 \mathrm{~mL})\end{array}$ & $\begin{array}{c}\text { CA 0,12\% } \\
(250 \mathrm{~mL})\end{array}$ \\
\hline Valor & $\mathrm{R} \$ 12,50$ & $\mathrm{R} \$ 20,00$ & $\mathrm{R} \$ 22,00$ & $\mathrm{R} \$ 33,15$ & $\mathrm{R} \$ 33,45$ & $\mathrm{R} \$ 28,00$ \\
\hline
\end{tabular}

Três tubetes anestésicos foram imersos em cada agente, sendo somente o álcool $70 \%$ borrifado sobre os tubetes e mantido em recipiente plástico com tampa, e todos mantidos por cinco, dez e 15 minutos. Três tubetes anestésicos controle (retirados do local de armazenamento na FO-UFRGS) não foram imersos.

Após o tempo de exposição aos diferentes desinfetantes, os tubetes anestésicos que estavam imersos com quantidade do agente suficiente para cobri-los, foram retirados com uso de luvas e pinça estéreis e colocados sobre um campo estéril, a fim de simular a mesa operatória, mantendo-os por dez minutos para secagem natural. Após, todos os tubetes anestésicos, tanto os que sofreram processo de desinfecção quanto os controles, foram submetidos à coleta de material através da técnica chamada de Swab-rinse, na qual é realizado um esfregaço suave com Swab, em toda superfície. Em seguida, foram embebidos em caldo de tripticase de soja (TSB) e incubados a $37^{\circ} \mathrm{C}$ por 24 horas. Posteriormente a incubação, cada tubo foi agitado, vigorosamente, e alíquotas foram coletadas de cada um e diluídas em $\mathrm{NaCl}$ 0,9\% estéril. Alíquotas das suspensões diluídas foram inoculadas em placas de Petri contendo meio tripticase de soja ágar (TSA), sendo incubadas a $37^{\circ} \mathrm{C}$ por 24 horas.

A pesquisa foi realizada em Câmera de Fluxo Laminar com utilização de meios estéreis, além de luvas, pinças, tesouras, tubos Falcon e ponteiras amarelas 20-200uL também estéreis. Foi utilizado o protocolo de semeadura à chama para evitar a contaminação contida no ar ambiente. 
Após 24h na estufa, analisou-se o crescimento ou não de meios bacterianos, verificando a eficácia dos agentes de desinfecção testados. O resultado foi avaliado pela presença ou ausência de crescimento bacteriano. Considerou-se que, independentemente da quantidade, havendo turvação dos meios líquidos ou formação de colônias nas placas de Petri o meio de desinfecção não foi efetivo.

\section{Resultados}

Como resultado dos experimentos realizados observou-se turvação dos meios líquidos e crescimento bacteriano nas placas de Petri com amostras imersas em D (Figura 1), SN, em todos os tempos experimentais. A turvação das placas de AG e SN confirma a necessidade de desinfecção dos tubetes anestésicos.

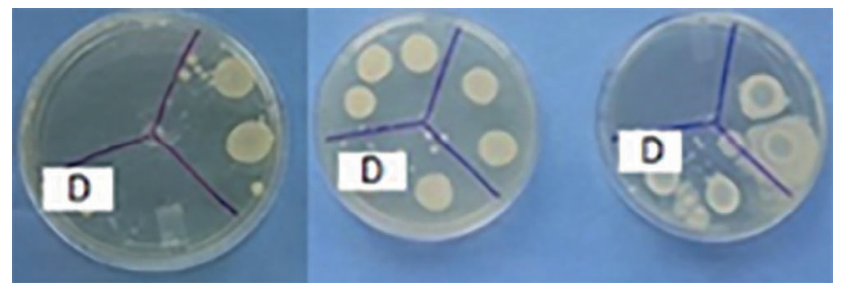

Figura 1 - Placas de Petri que apresentaram crescimento bacteriano do grupo controle $D$ nos tempos de cinco, dez e 15 minutos

Fonte: autores.

Em relação às amostras dos agentes dos grupos I, CA $2 \%$, CAL $0,12 \%$ (Figura 2) e CAL $2 \%$ não houve turvação dos meios líquidos TSB e crescimento bacteriano nas placas de Petri em nenhum tempo de exposição, evidenciando a eficácia destes agentes. Contudo, tanto o grupo A (Figura 3) quanto o grupo CA $0,12 \%$ demonstraram eficácia apenas no tempo de 15 minutos, não sendo indicados nos demais tempos.

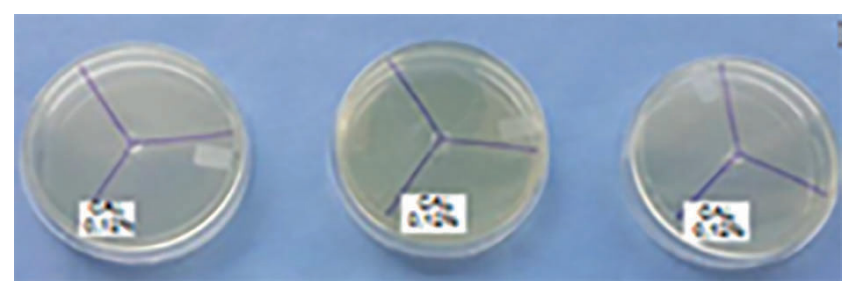

Figura 2 - Placas de Petri que não apresentaram turvação do meio e crescimento bacteriano nas amostras contendo $C A L$ $0,12 \%$ nos tempos de cinco, dez e 15 minutos

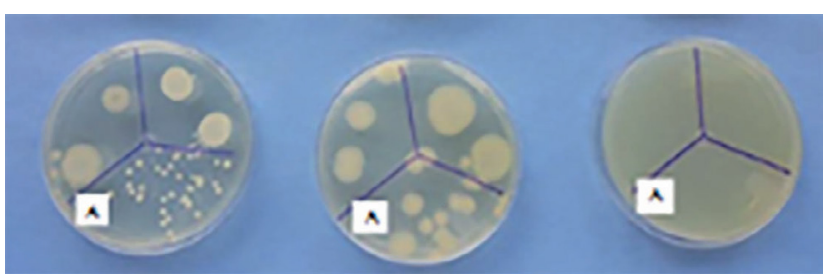

Figura 3 - Placas de Petri referentes às amostras com A nos tempos de cinco, dez e 15 minutos

Todos resultados obtidos foram compilados na tabela a seguir (Quadro 2), exibindo a presença ou ausência de crescimento bacteriano nas Placas de Petri com os agentes utilizados nos tempos de cinco, dez e quinze minutos.

Quadro 2 - Presença ou ausência de crescimento bacteriano nas Placas de Petri

\begin{tabular}{|c|c|c|c|c|c|c|c|c|}
\hline & $\begin{array}{c}\mathrm{SN} \\
(n=9)\end{array}$ & $\begin{array}{c}\text { I } \\
(n=9)\end{array}$ & $\begin{array}{c}A \\
(n=9)\end{array}$ & $\begin{array}{c}\text { AG } \\
(n=9)\end{array}$ & $\begin{array}{c}\text { CAL } 0,12 \% \\
(n=9)\end{array}$ & $\begin{array}{c}\text { CAL } 2 \% \\
(n=9)\end{array}$ & $\begin{array}{c}\text { CA } 0,12 \% \\
(n=9)\end{array}$ & $\begin{array}{c}\text { CA } 2 \% \\
(n=9)\end{array}$ \\
\hline Cinco minutos & $\begin{array}{c}\text { Presente } \\
(+)\end{array}$ & $\begin{array}{c}\text { Ausente } \\
(-)\end{array}$ & $\begin{array}{c}\text { Presente } \\
(+)\end{array}$ & $\begin{array}{c}\text { Presente } \\
(+)\end{array}$ & $\begin{array}{l}\text { Ausente } \\
(-)\end{array}$ & $\begin{array}{c}\text { Ausente } \\
(-)\end{array}$ & $\begin{array}{c}\text { Presente } \\
(+)\end{array}$ & $\begin{array}{c}\text { Ausente } \\
(-)\end{array}$ \\
\hline Dez minutos & $\begin{array}{c}\text { Presente } \\
(+)\end{array}$ & $\begin{array}{c}\text { Ausente } \\
(-)\end{array}$ & $\begin{array}{l}\text { Presente } \\
(+)\end{array}$ & $\begin{array}{l}\text { Presente } \\
(+)\end{array}$ & $\begin{array}{c}\text { Ausente } \\
(-)\end{array}$ & $\begin{array}{c}\text { Ausente } \\
(-)\end{array}$ & $\begin{array}{l}\text { Presente } \\
(+)\end{array}$ & $\begin{array}{c}\text { Ausente } \\
(-)\end{array}$ \\
\hline 15 minutos & $\begin{array}{c}\text { Presente } \\
\quad(+)\end{array}$ & $\begin{array}{c}\text { Ausente } \\
(-)\end{array}$ & $\begin{array}{c}\text { Ausente } \\
(-)\end{array}$ & $\begin{array}{c}\text { Presente } \\
(+)\end{array}$ & $\begin{array}{c}\text { Ausente } \\
(-)\end{array}$ & $\begin{array}{c}\text { Ausente } \\
(-)\end{array}$ & $\begin{array}{c}\text { Ausente } \\
(-)\end{array}$ & $\begin{array}{c}\text { Ausente } \\
(-)\end{array}$ \\
\hline
\end{tabular}

\section{Discussão}

As superfícies de equipamentos odontológicos estão contaminadas com a presença de microrganismos ${ }^{2}$ e a partir dos dados obtidos nesta pesquisa é possível concordar com esta afirmação. Os tubetes anestésicos utilizados como grupo controle (D e SN), retirados do seu local de armazenamento, comprovam a necessidade de desinfecção dos mesmos por agentes químicos eficazes.

$\mathrm{O}$ uso de tubetes anestésicos sem adequado processo de desinfecção não é recomendado, pois resultaria na quebra da cadeia asséptica dos procedimentos cirúrgicos odontológicos. Além desse fator, deve-se levar em consideração questões de biossegurança e um possível risco a infecções cruzadas por doenças como HIV, Hepatite B entre outras, casos já relatados em procedimentos odontológicos 8 .

A escolha dos agentes para desinfecção foi baseada nas normas da ANVISA (2010) ${ }^{4}$ e segundo Silva $^{2}$ (2002), sendo eles o A, I, CA 0,12\%, CA $2 \%$, CAL $0,12 \%$ e CAL $2 \%$. Os produtos demonstram ser eficientes devido a sua comprovada eficácia, ao baixo custo e a facilidade de manuseio dos mesmos.

Sendo assim, os autores recomendam o uso dos agentes I, CA $2 \%$, CAL $0,12 \%$ e CAL $2 \%$ que mostraram eficácia em todos os tempos de exposição. Os 
resultados de efetividade das soluções concordam com os já apresentados no estudo de Silva² (2002).

Devido à inexistência de um protocolo específico para a desinfecção dos tubetes anestésicos, muitos profissionais se questionam sobre qual composição de agente químico utilizar e o tempo de exposição efetivo. A partir disso, o conhecimento de procedimentos que visam a não contaminação ou infecção por agentes patológicos são de extrema importância para manter a cadeia asséptica existente na área da saúde, principalmente no âmbito de cirurgias odontológicas.

Dessa forma, os autores entendem ser de grande valia o presente estudo que busca avaliar os agentes realmente efetivos na desinfecção dos tubetes anestésicos, fornecendo informações pertinentes para a comunidade acadêmica e aos demais profissionais de saúde.

Entende-se que há a necessidade de estudos que visem verificar se pode haver alteração da formulação dos tubetes anestésicos pelos agentes desinfectantes.

\section{Conclusões}

O presente estudo constatou a necessidade de desinfecção dos tubetes anestésicos para procedimentos cirúrgicos ambulatoriais, vide a contaminação nas amostras controles. Os agentes considerados efetivos pelo estudo foram: I, CA $2 \%$, CAL $0,12 \%$, CAL $2 \%$ em apenas cinco minutos de exposição e, por outro lado, os agentes CA 0,12\% e o A $70 \%$, após 15 minutos de exposição.

\section{Albstract}

Objective: to evaluate the effectiveness of disinfection of anesthetic tubes, in vitro, for surgical procedures using $70 \%$ alcohol (A), iodine compound (I), $0.12 \%$ aqueous solution of chlorhexidine digluconate $(0.12 \%$ CA), $2 \%$ aqueous solution of chlorhexidine digluconate $(2 \%$ CA), $0.12 \%$ alcohol solution of chlorhexidine digluconate $(0.12 \% \mathrm{CAL})$, and $2 \%$ alcohol solution of chlorhexidine digluconate ( $2 \% \mathrm{CAL})$. Materials and method: distilled water $(D)$ and no agent $(S N)$ were used as control groups. After exposure times of 5, 10 and 15 minutes to disinfectant agents, samples were collected with swab, which had been previously soaked in trypticase soy broth (TSB), and the tubes were incubated at $37^{\circ} \mathrm{C}$ for 24 hours. The samples were inoculated in Petri dishes with half trypticase soy agar (TSA) and incubated at $37^{\circ} \mathrm{C}$ for 48 hours, verifying the presence or absence of Colony-Forming Units (CFU). Results: the study revealed that $A$ and $0.12 \%$ CA were only effective after 15 minutes of exposure. The $2 \%$ $C A, 0.12 \% C A L, 2 \% C A L$, and I were effective in experiment times of 5, 10, and 15 minutes. Control groups ( $D$ and $S N$ ) showed bacterial growth in all experiment times. Conclusions: the agents tested, which showed disinfection effectiveness at just 5 minutes associated with low cost and ease of handling, were the following: I, $2 \% C A, 0.12 \% C A L$, and $2 \%$ CAL. The results of the control groups highlight the need for disinfecting the tubes prior to use.

Keywords: Disinfection. Asepsis. Chemical compounds. Oral surgery.

\section{Referências}

1. Block SS. Definition of Terms. In: Desinfection, sterilization and preservation. 5. ed. Philadelphia: LWW; 2001. p. 19-30.

2. Silva CRG, Jorge AOC. Avaliação de desinfetantes de superfície utilizados em Odontologia. Pesqui. Odontol. Bras 2002; 16(2):107-114.

3. Mazzola PG, Angela Faustino Jozala; Letícia Célia de Lencastre Novaes; Patricia Moriel; Thereza Christina Vessoni Penna et al. Minimal inhibitory concentration (MIC) determination of disinfectant and/or sterilizing agents. Brazilian Journal of Pharmaceutical Sciences 2009; 45(2).

4. Brasil. Farmacopeia Brasileira. Agência Nacional de Vigilância Sanitária, Brasília, 2010, volume 2, p. 546.

5. Venturelli AC; Fernando César Torres; Renata Rodrigues de Almeida-Pedrin; Renato Rodrigues de Almeida; Marcio Rodrigues de Almeida; Fernando Pedrin Carvalho Ferreiraet al. Avaliação microbiológica da contaminação residual em diferentes tipos de alicates ortodônticos após desinfecção com álcool 70\%. Rev Dent Press Ortodon Ortop Facial 2009; 4(4):43-52.

6. Moryia T, Módena JLP. Asepsy and antisepsy: technics of sterilization. Medicina (Ribeirão Preto) 2008; 41(3):265-73.

7. Costa F, Felli A, Elisa V. Periculosidade dos produtos e resíduos químicos da atenção hospitalar. Cogitare Enfermagem 2012; 17(2):322-30.

8. Angelillo IF; A. Bianco; C. G. A. Nobile; M. Pavia et al. Evaluation of the efficacy of glutaraldehyde and peroxygen for disinfection of dental instruments. Lett Appl Microbiol Oxford 1998; 27(5):292.

Endereço para correspondência:

Adriana Corsetti

Endereço: Gonçalo de Carvalho, 271 apto 1002

CEP: 90035-170 Porto Alegre, RS, Brasil

Telefone: (51) 99972-5227

E-mail: adriana.corsetti@ufrgs.br

Recebido: 31/10/2016. Aceito: 02/12/2016. 